\title{
O LUGAR E A MEMÓRIA NA EXPERIÊNCIA DE UM PROGRAMA DE EDUCAÇÃO PATRIMONIAL REALIZADO EM CAAPORÃ - PARAÍBA
}

\author{
THE PLACE AND MEMORY IN THE EXPERIENCE OF A HERITAGE EDUCATION \\ PROGRAM CARRIED OUT IN CAAPORÃ - PARAÍBA STATE
}

\author{
Willian Carboni Viana ${ }^{1}$ \\ Valmir Manoel Mendes Junior ${ }^{2}$
}

RESUMO: O artigo apresenta o uso da Arqueologia Pública na experiência das atividades de educação, desenvolvidas no âmbito de um projeto de gestão de bens arqueológicos no município de Caaporã (Paraíba). As ações educacionais partiram das concepções da formação social dos sujeitos envolvidos, associando o lugar e a memória em contraposição a cultura enquanto mercadoria. A socialização da interpretação pública da arqueologia regional, oportunizou a conscientização sobre temas pouco explorados no ensino regular, como, o conhecimento sobre história através da cultura material ou em relação a populações pré-coloniais que habitavam a região, reforçando, assim, o papel ciência arqueológica na construção das identidades ou mesmo da autoafirmação individual e coletiva.

Palavras-chave: Arqueologia Pública. Educação Patrimonial. Identidade. Memória.

ABSTRACT: The article presents the use of Public Archeology in the experience of educational activities, developed within the scope of a project for the management of archaeological assets in the municipality of Caaporã (Paraíba state). The educational actions started from the conceptions of the social formation of the subjects involved, associating place and memory in opposition to culture as a commodity. The socialization of the public interpretation of regional archeology provided an opportunity to raise awareness of themes that little explored in regular education, such as knowledge of history through material culture or in relation to pre-colonial populations that inhabited the region, thus reinforcing the role of archeological science in construction of identities and collective self-affirmation.

Keywords: Public Archeology. Heritage Education. Identity. Memory.

\footnotetext{
${ }^{\text {I }}$ Doutorando em Geografia no Departamento de Geografia da Faculdade de Letras da Universidade do Porto (Portugal). Mestre em Arqueologia pelo Instituto Politécnico de Tomar - IPT/Universidade de Trás-osMontes e Alto Douro - UTAD (Portugal). Geógrafo pela Universidade do Extremo Sul Catarinense UNESC (Brasil).E-mail: willian.cienciashumanas@gmail.com.

${ }^{2}$ Graduado em Arqueologia pela Pontifícia Universidade Católica de Goiás - PUC/GO. Diretor da Mendes Archeo Assessoria em Arqueologia. E-mail: mendesarcheologia@gmail.com.
} 


\section{INTRODUÇÃO}

O lugar e a memória são dois conceitos fundamentais para a realização de uma Arqueologia Pública integral (HORTA; GRUNBERG; MONTEIRO, I999). Lugar, enquanto conceito multifacetado e exposto às diversas percepções, pode ser tomado como uma porção do espaço geográfico onde a vida acontece, sendo a unidade mais próxima do ser humano e que assenta a memória.

O significado de um lugar está associado a forma como o território é usado ou valorizado por um ou mais grupos sociais. As experiências das pessoas dão sentido ao lugar, que pode ser um rio, uma praça, um monumento, um templo, uma ruína, um sítio arqueológico, ou ainda o conjunto de todos eles, expondo atributos do passado e do presente (CARDOSO et al, 2017).

Por memória, entende-se a capacidade de armazenamento de informações e experiências, o que, junto de outros elementos, permitem a criação do sentimento de pertencimento. O patrimônio arqueológico está inserido em um grupo alargado de valores coletivos, agrupados ante a denominação geral de patrimônio cultural. A conexão entre o passado e o presente é feita pela memória (CURA et al., 2017).

Portanto, esse patrimônio como um todo, material ou imaterial, constitui-se desse agrupamento maior, formador de compósitos repletos de significados reconhecíveis, por um indivíduo ou comunidade (CURA et al., 2019).

A valorização do patrimônio arqueológico perpassa, essencialmente, em selecionar a melhor estratégia em meio aos muitos discursos e agenciamentos relacionados ao local e o contexto de sua inserção (OOSTERBEEK, 2003, p. 35I).

Neste sentido, a Arqueologia Pública, através da educação patrimonial, tem em seu cerne a proposição de ações de compartilhamento do conhecimento arqueológico. As práticas desenvolvidas na educação patrimonial, que historicamente seguiram o amadurecimento da Arqueologia enquanto disciplina, bem como das ciências afins, encontra o seu potencial no entendimento da própria Arqueologia como uma atividade social múltipla (histórica, política, econômica, filosófica, geográfica, institucional, etc.). 
O que não deixa de implicar em posicionamentos teóricos e éticos que comportam diferenças, tanto nos processos de seleção de temas quanto nas opções de ferramentas teórico-metodológicas para a sua disseminação (COSTA, 2019).

A realização de ações educativas direcionadas à preservação, divulgação e conscientização sobre bens culturais, incluindo-se os arqueológicos, está manifesta desde a fundação do Instituto do Patrimônio Histórico e Artístico Nacional (IPHAN) na década de 1930. Entretanto, agregaram-se novos contornos a partir dos anos 70, no seio do movimento internacional denominado "Public Archaeology", iniciado na Escola Norteamericana de Antropologia/Arqueologia por McGimsey (COSTA, 2019).

No Brasil, a metodologia da educação patrimonial foi sistematizada e vinculada nas discussões preservacionistas da década de 1980, inspirada no modelo inglês de educação museal, especificamente, depois do $\mathrm{I}^{\mathrm{o}}$ Seminário do Uso Educacional de Museus e Monumentos (COSTA, 2019). Seguindo, portanto, os tratados e protocolos estabelecidos nesse evento, a educação patrimonial passou a integrar os organogramas dos órgãos responsáveis pela gestão e manutenção de atividades culturais - o que foi previsto no Plano Nacional de Educação (PNE) e nas diversas leis e políticas públicas que regem a matéria.

Atualmente, e particularmente nos últimos io anos, as reflexões propostas como fundamento da educação patrimonial, partem da relação com a formação social libertadora, pautada na pedagogia de Paulo Freire - ainda que ele não tenha escrito sobre o assunto de modo "stricto sensu".

Contrapondo-se, então, a concepção de cultura enquanto mercadoria que produz identidades, por primeiro estabelecida pelo Estado-Nação (Militar), depois apropriada por empresas transnacionais, a consolidar a difusão de cultura que parte dos países centrais para os países periféricos e/ou semiperiféricos (Soft Power).

Ruas, casas, a esfera pública, o mundo da vida, seus sentidos e rituais, manifestações culturais e simbólicas, os costumes e as tradições, o sagrado e o não-sagrado, todos esses - e outros - são elementos formadores dos compósitos socioculturais, determinantes para a compreensão das materialidades e imaterialidades que percorrem a 
capacidade de significar e dar significado, refletindo o exercício da memória que, individual ou coletiva, dá sentido aos lugares habitados.

Neste quesito, o ambiente escolar assume papel excepcional na promoção, mediação e conscientização dos entendimentos acima citados, envolvendo métodos permissivos a interação entre pesquisadores e comunidade de modo a formar agentes multiplicadores e preservadores do próprio patrimônio cultural.

Assim, a efetivação de um sentimento de pertença desvinculado da monoidentidade nacional intentada pelo Regime Militar no Brasil, tem sido largamente apresentado como multiculturalismo ou multietnicidade, a partir da educação patrimonial, nos ambientes formais e informais, dentro e fora da escola.

Aqui se destaca a escola, cujas atividades de educação patrimonial são empreendidas tanto com os professores, quanto com os mais jovens, que consequentemente podem se tornar agentes multiplicadores dos conteúdos passados (HORTA; GRUNBERG; MONTEIRO, 1999), geralmente atrelada à licenciamentos de obras de engenharia, demonstrando certa preocupação do Estado, mas ao mesmo tempo não atingindo um público maior em quantidade e qualidade.

Por isso, o trabalho pensado para uma ação educativa desse cunho, precisa necessariamente levar em consideração o contexto dos participantes, certo que o Patrimônio Cultural tem a ver com aquilo que é transmitido ou deixado de geração em geração.

Fazer com que as pessoas consigam perceber o seu próprio patrimônio e tenham uma relação de valoração em relação a ele deve ser a centralidade das ações, indissociável ao lugar e a memória de inserção dos atores sociais adjacentes.

Deste modo, verificou-se a necessidade da elaboração de um programa de Arqueologia Pública que desse o tom de uma educação patrimonial integral, concordante com as características do empreendimento a ser instalado, quando vinculado ao licenciamento ambiental - o que vem ao caso neste escrito.

O empreendimento em questão, ao qual este programa de educação faz parte, situa-se na zona rural do município de Caaporã, no litoral Sul do estado da Paraíba. É 
caracterizado pela instalação de uma fábrica de cimentos e áreas de extração de argila e calcário, pertencentes a Votorantim $\mathrm{S} / \mathrm{A}^{3}$, nas proximidades de io sítios arqueológicos.

Diante do exposto, o IPHAN emitiu o parecer técnico com o número de processo I69/2015/CNA/DEPAM/IPHAN-PB, indicando a necessidade da execução de um programa de gestão dos sítios arqueológicos registrados e de outros bens culturais. O que foi materializado com um amplo levantamento histórico e cultural material e imaterial local, no salvamento dos sítios supracitados, na curadoria e análise do material resgatado nos sítios, bem como na realização do plano ampliado de Arqueologia Pública a envolver ações educativas de conscientização.

Dentro da interação entre o licenciamento ambiental e a arqueologia preventiva, estiveram as atividades de Educação Patrimonial, conforme previsto nas diversas Leis Federais que regem o assunto (BRASIL, I96r; BRASIL, 1986; BRASIL, 1988a; BRASIL, I988b; BRASIL, 1997; BRASIL, 2002; BRASIL, 2018).

Deste modo, as ações para a educação patrimonial partiram de uma aproximação com a abordagem construtivista, tendo como público-alvo alunos e professores da rede municipal de ensino de Caaporã. O objetivo essencial foi a criação de um sentimento do público envolvido sobre o seu próprio Patrimônio Cultural, com vistas à formar multiplicadores da preservação e valorização para as gerações futuras, sobre o seu patrimônio, o seu lugar e a sua memória.

\section{MATERIAIS E METODOLOGIA}

As jazidas de extração de calcário e argila, para a manutenção da fábrica de cimento a ser instalada, se situam nas dependências de três fazendas desmembradas, designadamente, Pindorama, Boqueirão e Fugida (Figura I).

\footnotetext{
${ }^{3}$ Participaram do Projeto Paraíba Fábrica de Cimentos e Lavras de Calcário e Argila da Votorantim S.A. (IPHAN/PB número ol408.00024I/2015-23), sob coordenação de Valmir Manoel Mendes Junior, os pesquisadores Ricardo Augusto S. Nogueira (consultor), Willian Carboni Viana, Leonardo Leal, Sandra V. de Santana, Ramon Henrique França e Claudete da Silva Nascimento.
} 
Figura I - Localização do empreendimento no município de Caaporã.

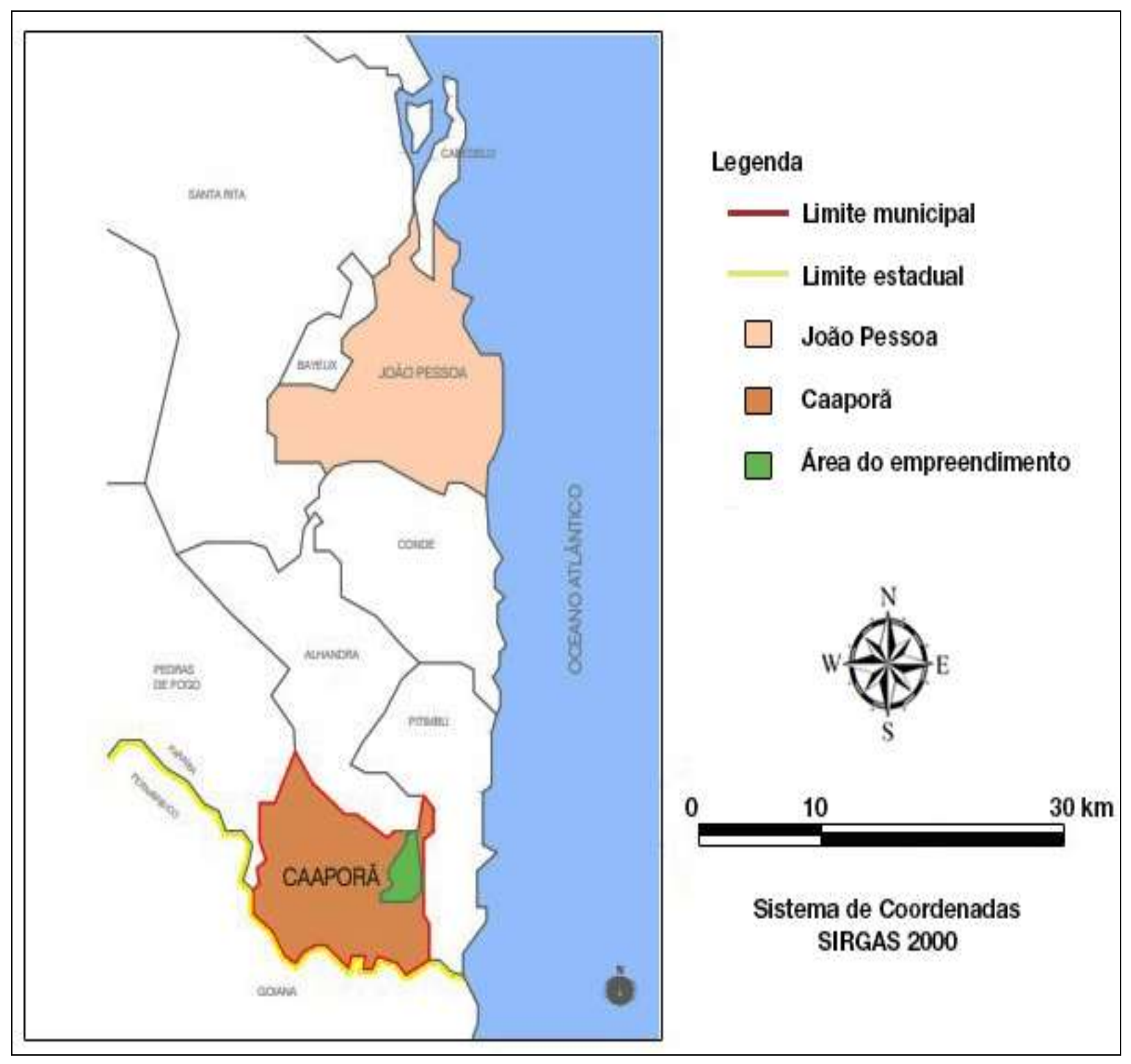

Fonte: MENDES JUNIOR (2017).

Em termos gerais, os sítios arqueológicos são compostos por materiais diversificados, que remetem a diferentes tempos. Esses locais são formados por vestígios culturais desde lítico lascado, cerâmica de origem tupi à materiais coloniais dos séculos XIX e início do XX, conforme descrito no Quadro I: 
Quadro I - Caracterização e localização dos sítios arqueológicos.

\begin{tabular}{|c|c|c|c|}
\hline \multirow[t]{2}{*}{ Sítio Arqueológico } & \multirow[t]{2}{*}{ Caracterização } & \multicolumn{2}{|c|}{$\begin{array}{c}\text { Localização UTM } \\
\text { (Zona 25M, WGS-84) }\end{array}$} \\
\hline & & Leste & Norte \\
\hline Boqueirão & Pré-colonial Lítico (lascado) & 0291790 & 9171092 \\
\hline Caaporã IV & Histórico, século XIX & 0291596 & 9169321 \\
\hline Carcará & Histórico, século XIX & 0294902 & 9171460 \\
\hline Cabuloso & $\begin{array}{l}\text { Multicomponencial, lito-cerâmico } \\
\text { pré-colonial atribuídos a grupos } \\
\text { tupi }\end{array}$ & 0295204 & 9172344 \\
\hline Coqueiro & $\begin{array}{l}\text { Histórico, remete à primeira } \\
\text { metade do século XX }\end{array}$ & 0291913 & 9170907 \\
\hline Macaíba & $\begin{array}{l}\text { Cerâmico pré-colonial, atribuído à } \\
\text { grupo tupi }\end{array}$ & 0291676 & 9173117 \\
\hline Taquara I & $\begin{array}{l}\text { Multicomponencial, lito-cerâmico } \\
\text { pré-colonial atribuídos a grupos } \\
\text { tupi, e com presença de material } \\
\text { histórico dos séculos XVIII e XX }\end{array}$ & 0295143 & 9171885 \\
\hline Taquara III & Histórico, séculos XIX e XX & 0294270 & 9172270 \\
\hline Tubarão & Histórico, séculos XIX e XX & 0293989 & 9168233 \\
\hline Zepelim & Pré-colonial Lítico (lascado) & 0294756 & 9174429 \\
\hline
\end{tabular}

Fonte: MENDES JUNIOR (2017).

Deste modo, levando-se em conta as características dos sítios arqueológicos, juntamente com o levantamento prévio e exaustivo sobre os demais patrimônios culturais locais, como, bens imóveis, arquitetônicos e imateriais-simbólicos, tais como, representações imaginárias, manifestações religiosas, danças do Maracatu, grupos de capoeira e a famosa literatura de cordel, foram traçadas estratégias de abordagem relacionando o local e a memória. 
Com a participação efetiva das Secretarias de Educação e Cultura de Caaporã, foram identificados os lugares de importância para as comunidades, onde se apreenderam as referências culturais materiais e imateriais, por meio de uma aproximação epistêmica e seguindo essa proposta de construção transversal, integrando de professores e alunos no processo educativo.

Para a participação das ações de Educação Patrimonial, a Secretaria de Educação do Município de Caaporã indicou 20 professores e duas escolas municipais, a saber, Severina Helena dos Santos Veloso e Maria Emília Valença, contemplando um total de 200 alunos (Figura 2).

Figura 2 - Localização das escolas municipais Severina Helena dos Santos Veloso e Maria Emília Valença em Caaporã/PB.

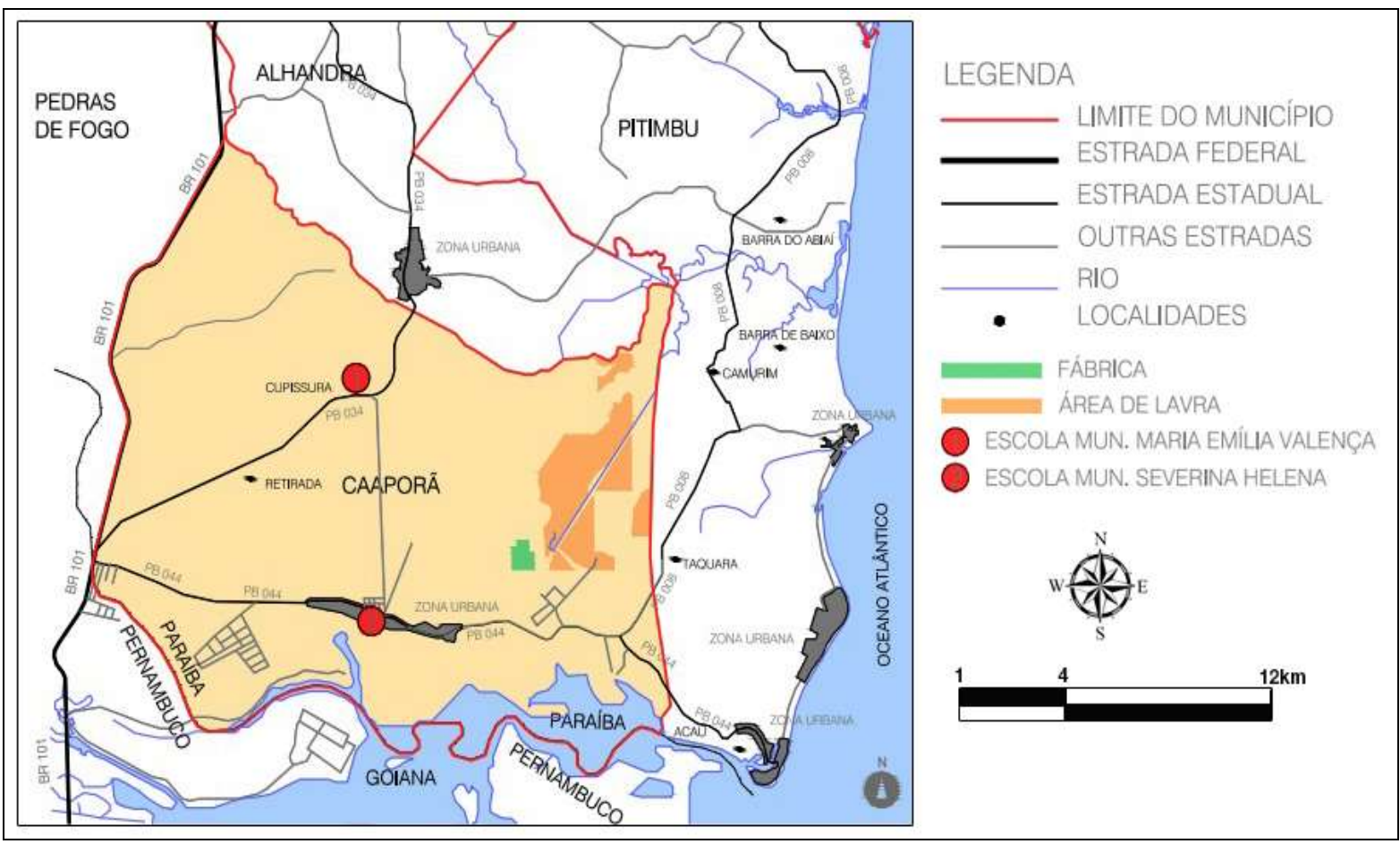

Fonte: MENDES JUNIOR (2017).

As atividades educacionais foram desenvolvidas entre março e junho de 2017, compreendendo cursos de inventários arqueológicos participativos, palestras, apresentações, aulas de campo e oficinas de fotografia, cerâmica, desenho, maquetes e 
literatura de cordel, além de um evento final expositivo envolvendo a comunidade em geral, denominado Semana do Patrimônio de Caaporã - com apoio da Prefeitura, conforme descrito no Quadro 2.

Quadro 2- Roteiro das ações desenvolvidas.

\begin{tabular}{cc}
\hline Tipo de atividade & Público atingido \\
\hline $\begin{array}{c}\text { Capacitação em Inventários } \\
\text { Arqueológicos Participativos }\end{array}$ & Professores \\
\hline $\begin{array}{c}\text { Oficina de Inventários } \\
\text { Participativos }\end{array}$ & Alunos e Professores \\
\hline $\begin{array}{c}\text { Palestras e atividades com } \\
\text { Mestres tradicionais }\end{array}$ & Alunos e Professores \\
\hline
\end{tabular}

\begin{tabular}{cc}
\hline $\begin{array}{c}\text { Aulas em campo - visitação de } \\
\text { lugares culturais }\end{array}$ & Alunos e Professores \\
\hline Apresentações culturais locais & Alunos e Professores \\
\hline $\begin{array}{c}\text { Oficina de orientação sobre } \\
\text { fotografia digital }\end{array}$ & Alunos e Professores
\end{tabular}

$$
\begin{aligned}
& \text { Oficina de confecção de cerâmica } \\
& \text { arqueológica }
\end{aligned}
$$

Alunos

\begin{tabular}{cc}
\hline Oficina de desenho & Alunos \\
\hline $\begin{array}{c}\text { Oficina de e confecção de } \\
\text { maquetes }\end{array}$ & Alunos \\
\end{tabular}

\begin{tabular}{cc}
\hline Oficina de literatura de cordel & Alunos \\
\hline $\begin{array}{c}\text { Evento: Semana do Patrimônio } \\
\text { Cultural de Caaporã, com } \\
\text { exposições diversas e } \\
\text { apresentações culturais locais }\end{array}$ & $\begin{array}{c}\text { Alunos, Professores e } \\
\text { comunidade local }\end{array}$ \\
\hline
\end{tabular}

\section{- Democratizar o conhecimento;}

- Divulgar o ofício dos mestres tradicionais de Caaporã;

- Oportunizar a aproximação dos mestres tradicionais com a comunidade escolar;

- Apresentar o panorama arqueológico, constituído pelo patrimônio cultural précolonial e histórico;

- Conscientizar, estimular e trazer a abordagem do tema patrimônio cultural para o ambiente escolar.

Fonte: Elaborada pelos autores. 
O material didático utilizado foi de elaboração própria, contendo desde conceitos básicos ao panorama contextual da Arqueologia da região, em três livros, designadamente, “Educação Patrimonial Caaporã: inventários participativos”, "Educação Patrimonial Caaporã: Bens Culturais" e "Educação Patrimonial Caaporã: Caderno do Professor”. O material didático foi distribuído para todos os envolvidos (Figuras 3 e Figura 4).

Figura 3 - Livro didático sobre inventários participativos.

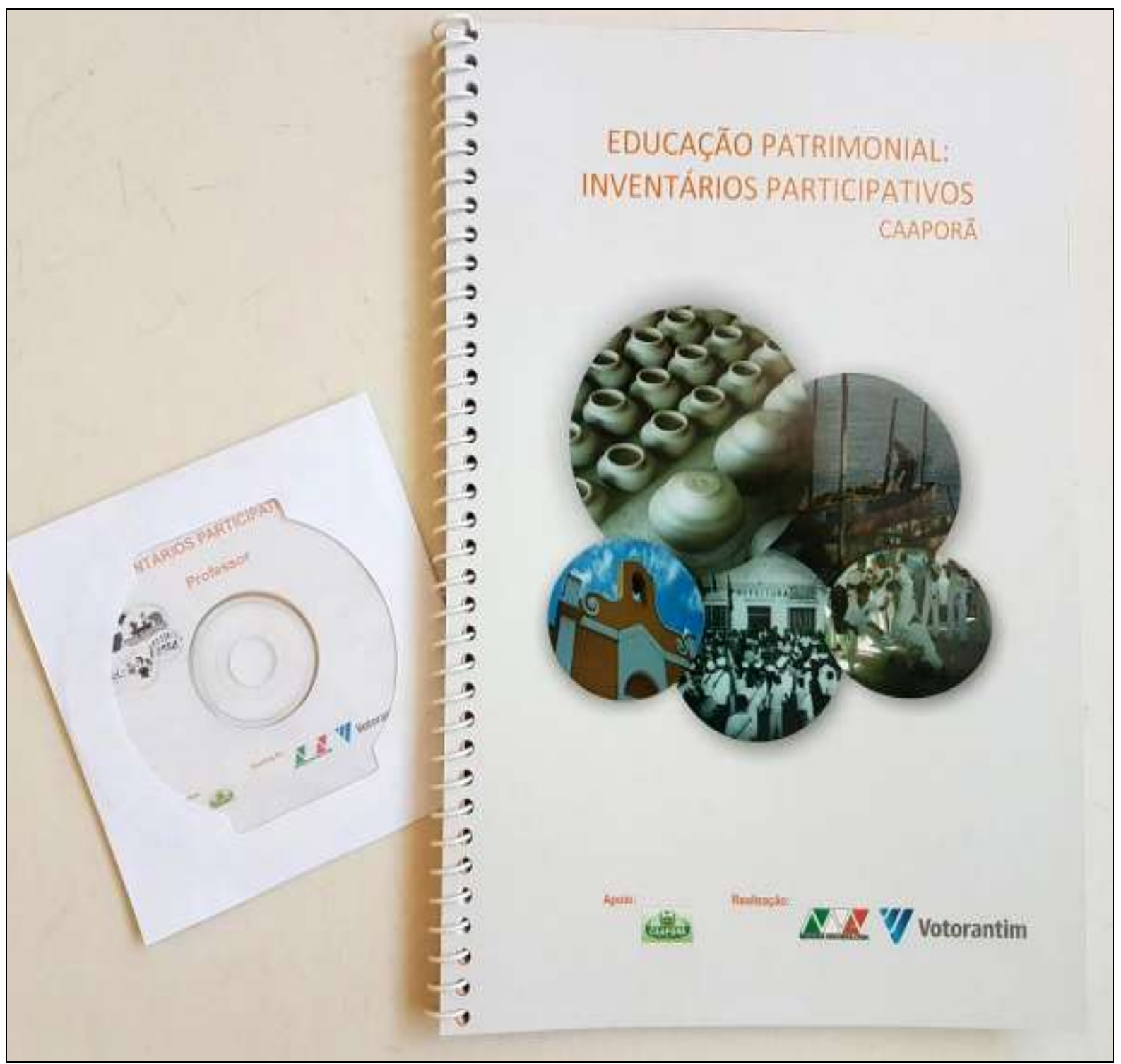

Fonte: MENDES JUNIOR (2017). 
Figura 4-Guias de bens culturais distribuídos aos alunos e professores.

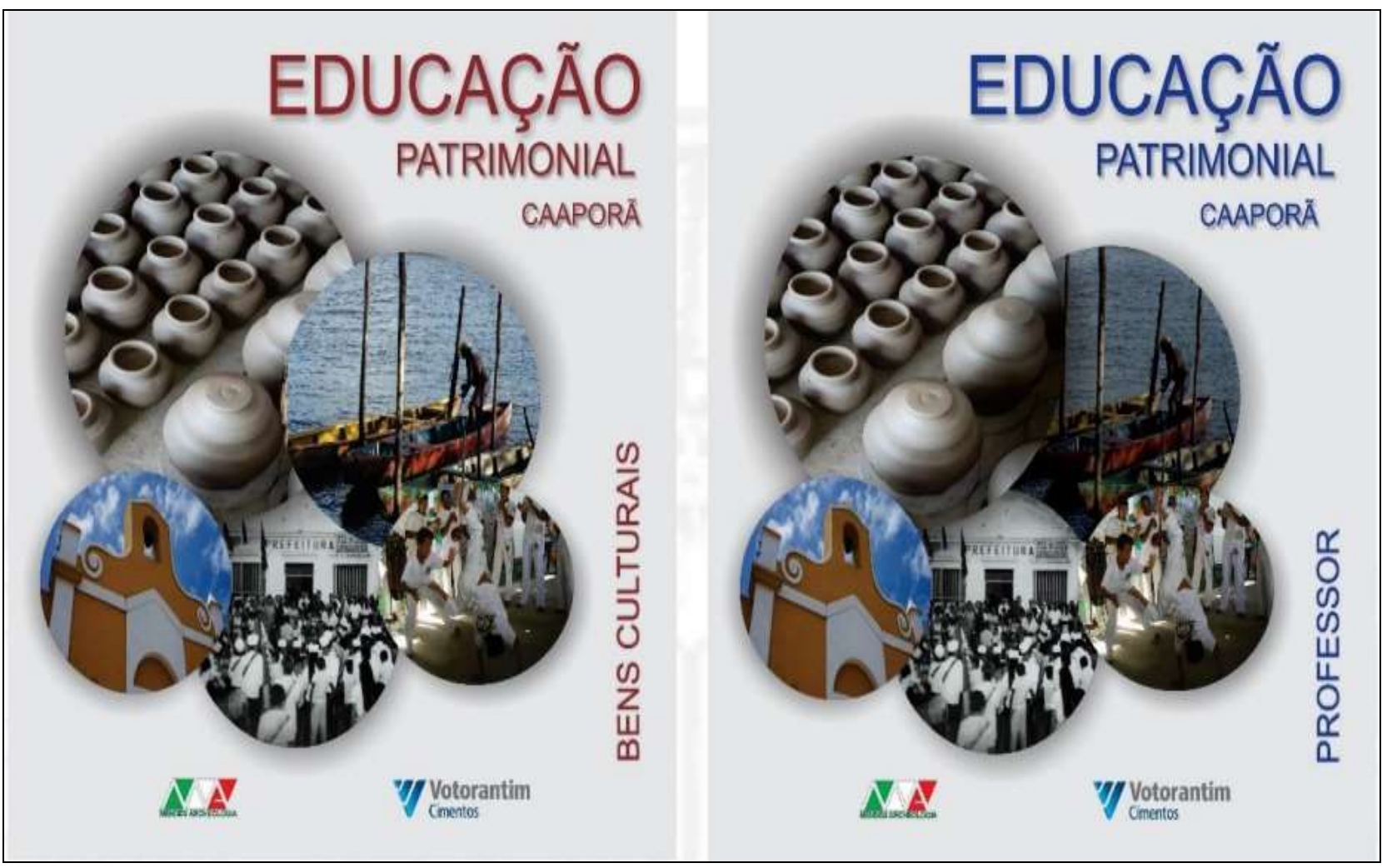

Fonte: MENDES JUNIOR (2017).

Particularmente, nas oficinas de inventário com os professores, a ideia girou na possibilidade do próprio corpo docente reconhecer os bens materiais, imateriais, móveis e imóveis do município, listando-os, descrevendo-os e, sobretudo, reconhecendo-os como parte da sua identificação individual e coletiva.

O programa da formação dos professores, relacionado aos inventários, abordou os seguintes temas: conceituação inicial sobre as definições de inventários; apanhado histórico sobre a sua utilização; marcos legais que balizam sua aplicação como ferramenta participativa na educação patrimonial e apropriação comunitária dos valores e bens culturais ativos. 
Em síntese, nas oficinas se apresentou a Arqueologia como uma ciência que estuda a vida e a cultura das populações do passado através da cultura material, encontrada nos sítios arqueológicos. Em relação a história de Caaporã e seu patrimônio material, foram apresentados alguns dos bens imóveis de importância para a sua formação territorial, como, as igrejas São Sebastião, São José e a primeira Batista a ser construída (hoje demolida), o Mercado Público e a primeira sede da Prefeitura Municipal, e no meio rural a igreja de Cupissura em homenagem à São Sebastião, o sobrado de Oiteiro do Amparo e a sede da Vila Operária da Fazenda Tabu.

Em relação ao patrimônio imaterial, ocorreram diálogos sobre as categorias de lugar, celebração, formas de expressão e saberes, como, o Porto de Gongaçari, a festa de São Pedro, cultos evangélicos, cultos da Umbanda, literatura de Cordel, grupos de Capoeira Cordão de Ouro, Maracatu de Baque Souto e Águia Dourada de Caaporã; a carpintaria naval, a pesca tradicional, os trançados, cerâmica, produção de óleo de dendê e a música com rabeca.

A metodologia se aproximou do patrimônio arqueológico e das referências culturais, buscando ampla reflexão sobre os bens patrimoniais, dentro dos preceitos da sustentabilidade, emponderamento e demonstração dos elementos importantes na luta por melhorias de vida e inclusão social dos diferentes grupos.

\section{RESULTADOS}

O conjunto de ações, proposto para as duas escolas da rede pública municipal de Caaporã e seu corpo docente, teve como foco oferecer meios que provocassem um diálogo reflexivo em relação a vida da comunidade (ou conhecer para pertencer).

No que diz respeito a experiência com a formação de inventários participativos, destinada aos docentes, pode-se dizer que se consistiu numa maneira inovadora de (re)conhecer parte dos diferentes contextos culturais do município - nos quais se inserem enquanto profissionais e indivíduos (Figura 5). 
Figura 5 - Formação dos Inventários Participativos com os professores.

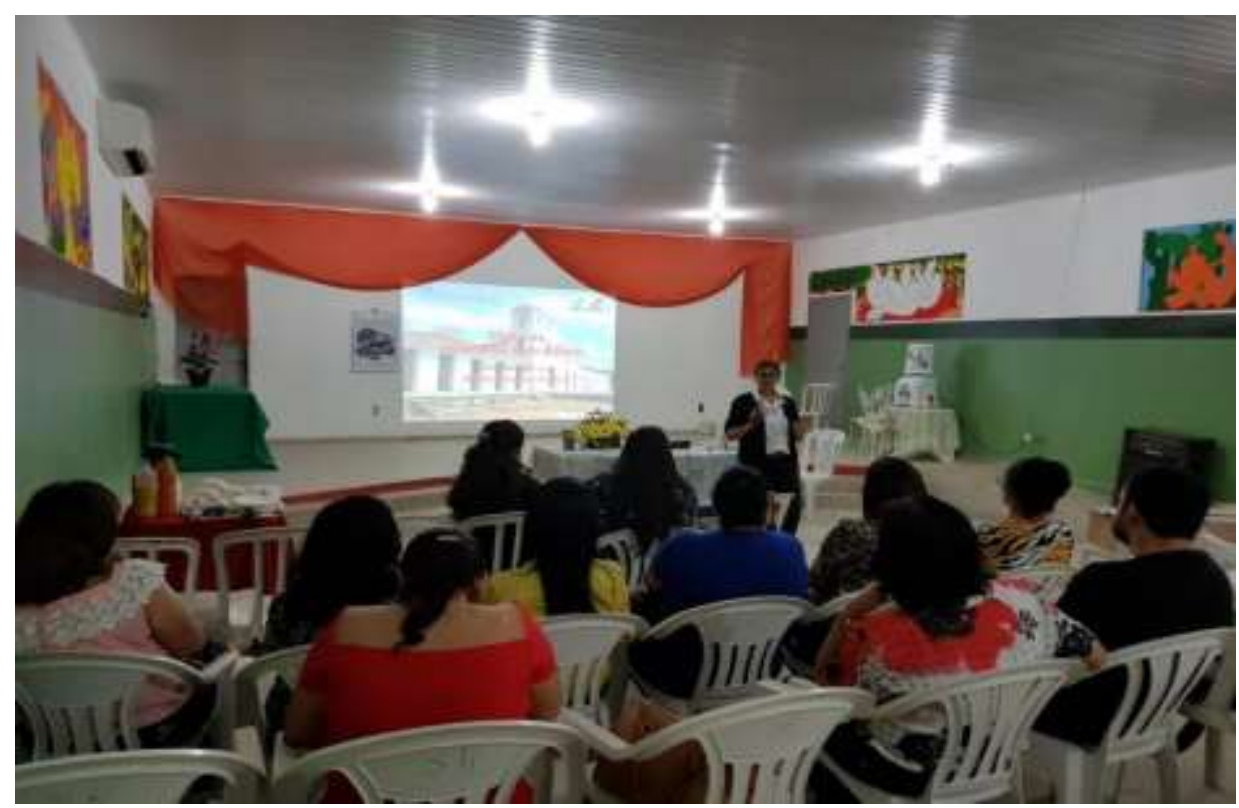

Fonte: MENDES JUNIOR (2017).

Nos encontros de realização dessa atividade formativa, foram discorridos assuntos básicos, a saber, sobre do que tratam as licenças ambientais e arqueológicas, apresentação dos seus órgãos fiscalizadores (IPHAN, SUDEMA), conceituação de cultura, patrimônio cultural e arqueológico, discutidos em paralelo à perspectiva da memória e do lugar; em sequência foram trazidos para o centro dos diálogos uma contextualização aprofundada em relação ao patrimônio cultural do município de Caaporã, sendo distribuídos os guias de bens culturais e caderno do professor.

Em relação à oficina dos inventários participativos, os mesmos conteúdos foram repassados aos alunos, de maneira didática.

A saída a campo contemplou a visitação, por parte de professores e alunos, de lugares de memória do município de Caaporã. O primeiro lugar de referência foram as igrejinhas de Taquara, localizadas na área rural do município de Pitimbu estão as igrejas de Nossa Senhora da Penha de França, datada de 1756 e Igreja Nossa Senhora do Rosário, erguida em $\mathrm{I} 843$. O local foi escolhido para participar do roteiro de visita porque a história e o processo de ocupação e formação da cidade de Caaporã detêm raízes comuns com os 
municípios de Alhandra (PB), Pitimbu (PB) e Goiana (PE). O distrito de Taquara, pertencente ao município de Pitimbu, proporcionou o desenvolvimento das três cidades.

No local, alunos e professores conheceram um pouco da história das igrejas e o processo de recuperação que o templo de Nossa Senhora da Penha de França (Figura 6) e Nossa Senhora do Rosário foram contempladas, através do termo de compromisso entre a Brenand Cimentos S.A. e a Superintendência do IPHAN da Paraíba. Em ambos os templos acontecem peregrinações com cortejo de imagens sacras, refletindo algumas das práticas tradicionais em determinadas épocas anuais.

Figura 6 - Professores em frente à Igreja da Penha.

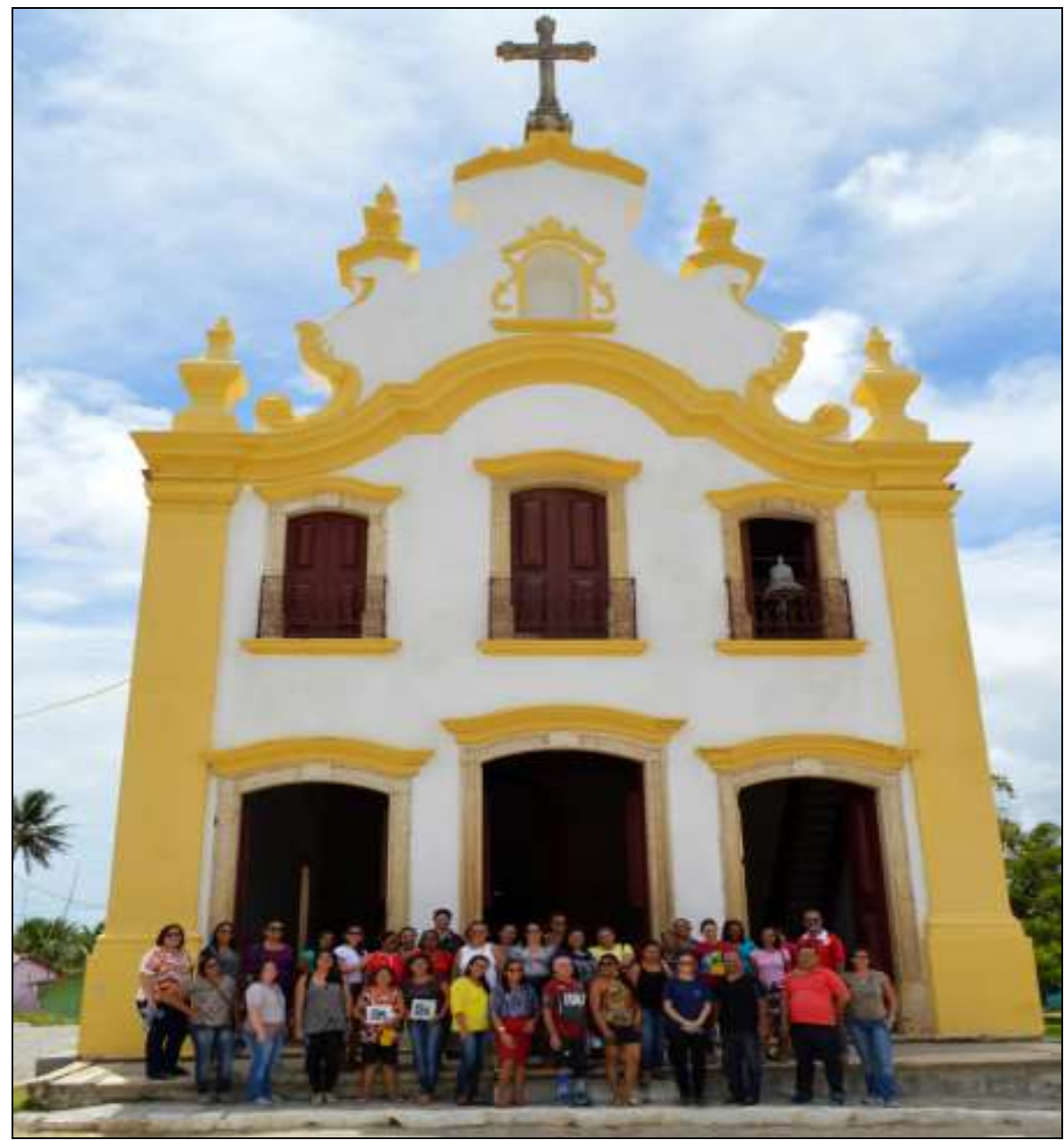

Fonte: MENDES JUNIOR (2017). 
Posteriormente, fez-se a visitação ao Museu de Arqueologia de Pitimbu, que está aos cuidados da arquidiocese. No local, que dispõe de um variado acervo de materiais que remetem ao período colonial, fez a explicação sobre os objetos expostos, retratando que os mesmos correspondiam ao contexto similar aos encontrados durante o programa de resgate arqueológico dos sítios do projeto em epígrafe, o que mais tarde se confirmou em laboratório se tratar de um mesmo contexto amplo de colonização.

Outro ponto marcante da execução da educação patrimonial foi a apresentação dos grupos de Maracatu de Caaporã. O Maracatu de Baque Solto, também conhecido na região como Maracatu Rural, Maracatu de Orquestra, Maracatu de Trombone ou Maracatu de Baque Singelo, trata-se de uma expressão cultural que ocorre durante as comemorações de carnaval e de Páscoa, compondo-se de dança típica, música e poesia, numa tradição estreitamente relacionada ao ciclo da cana-de-açúcar da zona da mata de Pernambuco.

Os mais antigos grupos de Maracatu foram criados nos engenhos, nos quais os seus criadores eram os trabalhadores do canavial, cortadores de cana, entre o final do século XIX e início do século XX. Portanto, trata-se de refletir sobre a importância do ciclo canavieiro para a constituição do território social local, o que fora percebido pelos alunos e professores (Figura 7).

Figura 7 - Apresentação do grupo de Maracatu de Baque Solto.

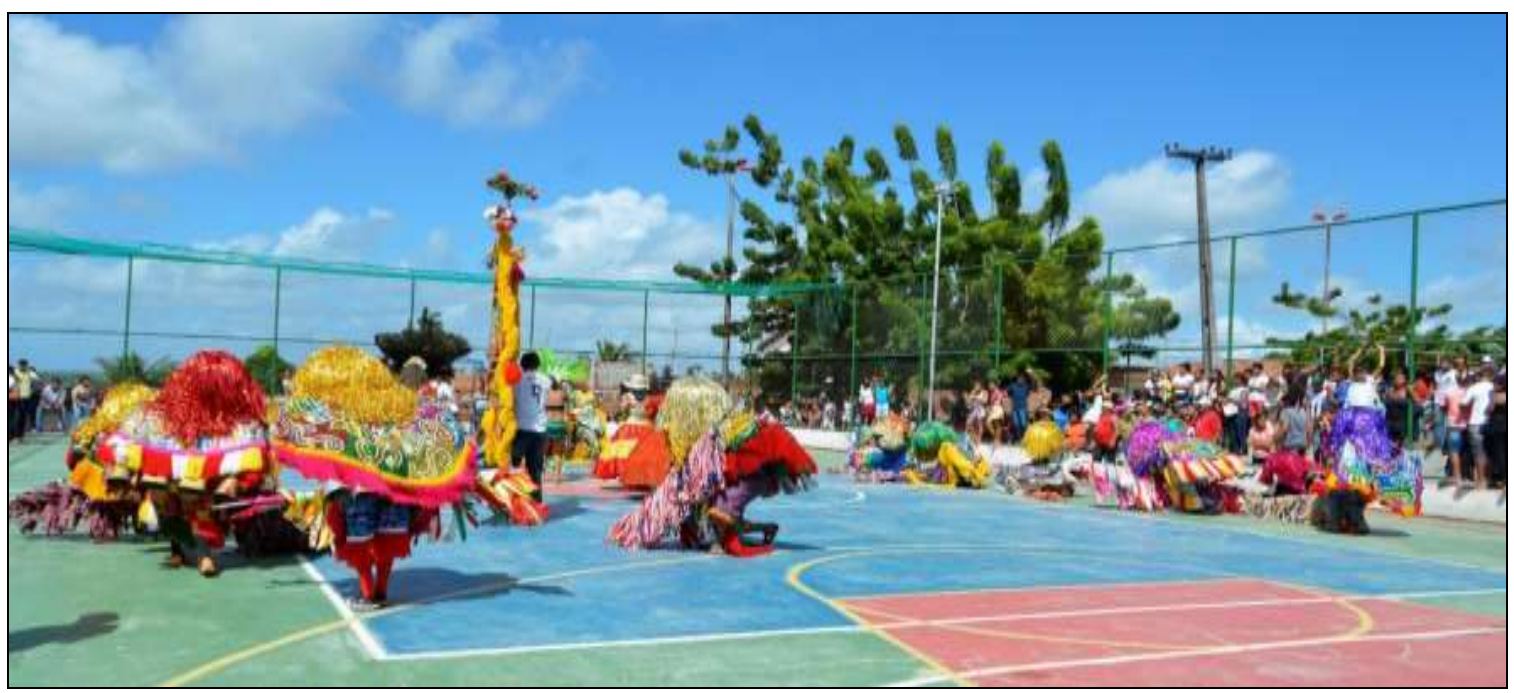

Fonte: MENDES JUNIOR (2017). 
$\mathrm{Na}$ oficina de elaboração das maquetes, os alunos replicaram em tamanho menor algumas construções mais antigas de Caaporã.

As oficinas de desenho contemplaram releituras da arquitetura histórica local

No que diz respeito a oficina de cerâmica arqueológica, os alunos tiverem aulas teóricas e práticas.

A oficina de desenho, teve início com uma palestra sobre releitura de obras de arte, sendo, no segundo momento, proposto aos alunos a realização de releituras das fotos que fizeram em campo ou daquelas inventariadas pelos professores durante a formação dos inventários participativos.

No que diz respeito a oficina da literatura de Cordel, ocorreu uma apresentação de conteúdo teórico, condizente a história da formação do Cordel, levando-se em consideração as suas formas poéticas em quadra, sextilhas, septilhas, rimas, diferenças e semelhanças com o repente, a incluir uma breve síntese sobre a Academia Brasileira de Literatura de Cordel, principais cordelistas e suas respectivas obras, bem como a demonstração dos cordéis feitos especialmente para áreas urbanas e daqueles para áreas rurais, como para o Distrito de Cupissura.

Os alunos logo demonstraram grande habilidade na produção dos cordéis, sobretudo, quando incentivados pela equipe de educação patrimonial, sendo produzidos pelos alunos, em grupo, 23 cordéis.

A oficina da literatura de cordel teve como integrante a cordelista local conhecida como Dona Lúcia, que auxiliou tanto a equipe de educação patrimonial na elaboração dos conceitos, quanto aos alunos da escrita dos seus cordéis.

Por fim, a exposição dos resultados ocorreu no evento intitulado "Semana do Patrimônio Cultural”, como previsto no cronograma, envolvendo além dos professores e alunos, a comunidade local.

Era a oportunidade de toda a comunidade conhecer o esforço e dedicação empreendidos e cujos resultados espelhavam um retrato cultural de Caaporã. 
O evento ainda incluiu iniciativas da Prefeitura Municipal de Caaporã, doando material gráfico sobre a pesca artesanal, construção naval em Porto de Gongaçari, sobre a Feira Livre da agricultura e pesca, casas de farinha com modos tradicionais de produção.

Diante do exposto, estudar a história de Caaporã tornou-se mais interessante e completo quando conectada aos territórios dos município vizinhos, antes denominada Porto dos Franceses, onde eram feitos escambos com indígenas.

A avaliação da educação patrimonial partiu da percepção subjetiva sobre o públicoalvo, neste caso, sobre os indícios que floresciam no decorrer as atividades, sendo gestos, olhares, expressões faciais, motivação, interesse, bem como outros elementos que se registram no plano do observador externo. Nesse ponto, os resultados alcançados foram considerados satisfatórios ao que o projeto de educação se propôs.

Nos aspectos endógenos, fez-se uma autoavaliação do desempenho da equipe de pesquisadores que aplicaram a educação patrimonial, considerando os prazos, objetivos alcançados e retorno por parte do município e direção da escola. Nessa questão, os feedbacks recebidos foram excelentes, sobretudo, no sentido de conversão a meio de troca de informações e socialização do conhecimento - o que não é habitual nas escolas da região.

A divulgação e extroversão da contextualização arqueológica foi empreendida de acordo com a realidade do local de inserção do sítio resgatado, com a distribuição de cartilhas próprias.

Isto posto em questão, conduz ao entendimento do universo sociocultural e do panorama histórico-cultural em que se inserem. Assim, compreende-se eu as atividades de educação patrimonial inseriram os professores e, pelo menos sensivelmente, os alunos no contexto da arqueologia local-regional, permitindo uma verdadeira aproximação entre essa ciência e a sociedade através do seu próprio patrimônio cultural.

\section{CONSIDERAÇÕES FINAIS}

Essas foram algumas das experiências vivenciadas, durante as ações de Educação Patrimonial desenvolvidas com alunos e professores do município de Caaporã, cujo plano abarcou as atividades de extroversão do conhecimento arqueológico. A abordagem 
participativa permitiu a valorização dos diferentes grupos sociais que formaram o município de Caaporã.

Neste sentido, a proposta das ações interpretativas sobre o passado perpassara pela participação ativa do público-alvo atingido, de modo a propiciar a formação de agentes multiplicadores da preservação do patrimônio arqueológico. O que destaca essa interação, levando para as escolas atividades extracurriculares instigantes, para alunos de instituições não habituadas em receber projetos externos desse cunho.

Portanto, o trabalho atingiu o objetivo pretendido, sensibilizando e conscientizando professores e alunos para o legado do patrimônio cultural.

Por fim, espera-se que a sistematização dos resultados descritos nesse escrito, possa auxiliar na apreensão e nas inferências mais propositivas sobre o espaço ocupado, usado, formado pelo contexto econômico, político e social, mas por fortes influências da Arqueologia. Promovendo, por esse meio, as transformações nos modos de visualização, identificação e tratamento da cultura.

\section{REFERÊNCIAS}

BRASIL. Lei Federal no 3.924, de 26 de julho de 196r. Dispõe sobre os monumentos arqueológicos e pré-históricos. Brasília-DF: Diário Oficial da União, seção I, I96r.

BRASIL. Resolução CONAMA no or, de 23 de janeiro de 1986. Dispõe sobre a avaliação de impacto ambiental, $1986 . \quad$ Disponível em: «http: \www.mma.gov.br/port/conama/index.cfm»>, acesso em: 20/II/202I.

BRASIL. Constituição Federal, de 05 de outubro de 1988. Brasília-DF: Governo Federal, 1988a.

BRASIL. Portaria IPHAN no o7, de or de dezembro de 1988. Dispões sobre a fiscalização das atividades que envolvem bens de interesse arqueológico e pré-histórico nas fases do licenciamento ambiental. Brasília-DF: Governo Federal, i988b. 
BRASIL. Resolução CONAMA nº o7, de 19 de dezembro de 1997. Dispõe sobre a avaliação de impacto ambiental, 1997. Disponível em: « http:\www.mma.gov.br/port/conama/index.cfm»>, acesso em: Io/I2/202I.

BRASIL. Portaria IPHAN nํ230, de 17 de dezembro de 2002. Dispões sobre a arqueologia nas fases do licenciamento ambiental. Brasília-DF: Governo Federal, 2002.

BRASIL. Portaria IPHAN no 375 , de 19 e setembro de 2018. Institui a política de patrimônio cultural material do IPHAN e dá outras providências. Brasília-DF: Governo Federal, 2018.

COSTA, Maria Clara. To do public Archaeology in Brazil: history, applicability and heritage education. Encontro de Investigação Jovem da Universidade do Porto. Porto: Livro de Resumos IJUP, 2019, p. I42-I42.

CARDOSO, Diogo da Silva; CURA, Sara Raquel; VIANA, Willian Carboni; QUEIROZ, Luiz A. Pacheco; COSTA, Maria Clara. Espacialidades e ressonâncias do patrimônio cultural: reflexões sobre identidade e pertencimento. Porto: Revista de Geografia e Ordenamento do Território (GOT), n. II, 2017, p. 83-98. Doi I0.17127/got/2017.11.004

CURA, Sara Raquel; CARDOSO, Diogo da Silva; QUEIROZ, Luiz Antonio P.; VIANA, Willian Carboni; COSTA, Maria Clara. Estratégias de preservação para o patrimônio cultural. Revista de Arqueologia Pública, I4(2), 2019, p. 63-78. Doiro.20396/rap.vi3i2.8657237 HORTA, Maria de Lourdes; GRUNBERG, Evelina; MONTEIRO, Adriane Queiroz. Guia básico de educação patrimonial. Brasília-DF: IPHAN, Museu Imperial, 1999, 58 p.

MENDES JUNIOR, Valmir Manoel. Programa de resgate arqueológico do projeto Paraíba fábrica de cimentos e lavras de calcário e argila Votorantim Cimentos S/A - fase de licenciamento. Brasília-DF: Mendes Archeologia Consultoria e Assessoria em Arqueologia, 2017, $169 \mathrm{p}$. 
OOSTERBEEK, Luiz Miguel. Da investigação à cenografia: construção de metarealidades. Porto: Departamento de Gestão de Território do IPT, 2003, 349-354. Disponível em: <https://goo.gl/xkfydB $>$, acesso em: 10/08/2021. 